\title{
Laparoscopic sleeve gastrectomy: a study of efficiency in treatment of metabolic syndrome components, comorbidities and influence on certain biochemical markers
}

\author{
Paweł A. Wojciak ${ }^{1}$, Patrycja Pawłuszewicz ${ }^{1}$, Inna Diemieszczyk ${ }^{1}$, Ewa Komorowska-Wojtunik ${ }^{2}$, Mikołaj Czerniawski ${ }^{1}$, \\ Adam Krętowski ${ }^{3}$, Agnieszka Błachnio-Zabielska ${ }^{4}$, Jacek Dadan ${ }^{1}$, Jerzy R. Ładny ${ }^{1}$, Hady Razak Hady ${ }^{1}$ \\ ${ }^{1}$ First Department of General and Endocrine Surgery, University Clinical Hospital of Bialystok, Bialystok, Poland \\ ${ }^{2}$ Intensive Care Unit, Ministry of the Interior Hospital of Bialystok, Bialystok, Poland \\ ${ }^{3}$ Department of Endocrinology, Diabetology and Internal Diseases, University Clinical Hospital of Bialystok, Bialystok, Poland \\ ${ }^{4}$ Department of Hygiene, Epidemiology and Metabolic Disorders, Medical University of Bialystok, Bialystok, Poland
}

\begin{abstract}
Introduction: The worldwide outbreak of morbid obesity forced contemporary medicine to adopt a multidisciplinary approach, which led to the description of metabolic syndrome (MS): a disease with self-aggravating components and one of the most important causes of morbidity and mortality. The need for therapeutic methods provoked development of metabolic surgery, which nowadays give possibilities for safe and effective treatment of all MS aspects simultaneously and improves many obesity-related comorbidities.

Aim: To assess the laparoscopic sleeve gastrectomy (LSG) procedure's efficiency in resolving MS components, treating comorbidities and to analyze the influence on certain biochemical markers in 1-year follow-up.

Material and methods: The retrospective cohort study of 211 patients after an LSG operation relied on statistical analysis of clinical data collected prospectively in follow-up visits. All applicable guidelines and bioethical recommendations were respected in this study.

Results: Assessment of bariatric efficiency proved the LSG operation to be effective in inducing significant weight loss and treating obesity. Analysis on the influence on MS components, such as non-insulin dependent diabetes (NIDDM), arterial hypertension (AH) and dyslipidemia, showed substantial improvement in all observed cases of these diseases. In the present study, follow-up also proved a partial remission inducing effect of this bariatric operation in many comorbidities, especially in chronic obstructive pulmonary disease, obstructive sleep apnea, peptic ulcer disease and depression. A desirable reduction in creatinine, C-reactive protein, uric acid, alanine aminotransferase, asparagine aminotransferase, $\gamma$-glutamyltransferase serum levels has also been observed during the follow-up.

Conclusions: The LSG is an effective method of treatment in all areas of metabolic syndrome, provides a significant positive clinical outcome in obesity-related comorbidities and induces desirable changes in inflammatory, kidney and liver related biomarkers.
\end{abstract}

Key words: metabolic syndrome, obesity, morbid obesity, bariatric surgery, laparoscopic sleeve gastrectomy. 


\section{Introduction}

Global development in all areas of human activity, especially economic, industrial, infrastructural, cultural and social, has led to the outbreak of a new worldwide occurring health-associated problem: obesity. Historically, it was understood simply as a disproportion between body weight and height accompanied by fat tissue excess, which affected few people and had no serious consequences for human health. Contemporarily, the constantly increasing prevalence and severity of obesity have evolved to the scale of a pandemic and provoked worldwide clinical research that led to the understanding of obesity as a disease complex, multifactorial and affecting many aspects of human physical and psychological health, which is preventable and treatable [1, 2]. Recent epidemiological data show alarming trends: over $30 \%$ of the world's population meet overweight or obesity diagnostic criteria (assessed most commonly by body mass index (BMI) calculations) and the predicted increase in these rates, with the actually observed growth trend in obesity's occurrence, gives an estimated percentage of $38 \%$ overweight people and another $20 \%$ obese by the year 2030 in the world population [3]. Modern medical knowledge considers obesity not only as an isolated disease, but also as a part and a cause of metabolic syndrome - an illness described in the AHA-NHLBI joint consensus in the year 2009 [4]. Further epidemiological research focused on metabolic syndrome (MS) proved its connection with increased cardiovascular disease (CVD) morbidity and mortality. There are also many other diseases with a clinically proven connection with obesity, for example sleep apnea, depression, chronic joint disease, certain kinds of neoplasms and many others. Thus, in the face of the global obesity pandemic and the fact that cardiovascular and other obesity associated diseases encompass the most common death and morbidity causes in the world population, an urgent need for effective therapeutic methods has emerged [5-7]. With the contribution to the development of general surgery, a number of operative techniques for obesity treatment were invented and a new branch of surgery has been created: bariatric surgery. Nowadays, bariatric surgery is scientifically proven to be the most effective method in curing not only obesity, but also accompanying metabolic disorders and other diseases related to obesity [8-11].
One of most widely performed techniques for obesity treatment is currently laparoscopic sleeve gastrectomy (LSG) [12]. It is clinically proven to induce a positive bariatric effect, understood as significant body weight loss and a therapeutic effect in components of metabolic syndrome [13-15]. The LSG method relies on surgically created anatomic changes in the gastrointestinal (GI) tract, which change and shorten food passage and additionally provide neurohormonal changes, affecting appetite regulation, GI tract motility and volume, absorption of nutrients and secretion of other hormones (including insulin) [16-18]. Our department is experienced in performing LSG and assessing its long-term effects.

\section{Aim}

The aim of this study was to analyze and statistically assess biometric and selected biochemical metabolism parameter data, collected in 1-year follow-up from patients operated on using the LSG procedure in our department for evaluation of the efficiency of this technique in treatment of morbid obesity.

\section{Material and methods}

This is a retrospective cohort study of $211 \mathrm{pa}$ tients undergoing the LSG procedure in the $1^{\text {st }}$ Department of General and Endocrinological Surgery of University Hospital in Bialystok in the years 2009-2018. Patients were qualified for surgical treatment of morbid obesity according to the Polish Guidelines on Metabolic and Bariatric Surgery [19]. In accordance with the European Personal Data Protection Regulation and recommendations of the Bioethical Committee of the Medical University of Bialystok, all patients received specially prepared forms, including information about personal data processing and storage, a description of the study course and aim with formal consent for participation in the study. The study was designed and conducted in accordance with STROBE guidelines and the report of the ISPOR task force $[20,21]$. Study inclusion criterion: patients qualified for laparoscopic sleeve gastrectomy. Patients were excluded when lack of necessary data or severe postoperative complications such as bleeding, anastomosis leak, septic complications and/or cardiopulmonary depression occurred, because of the significant impact of these complications on postoperative 
treatment course and patient clinical status, which might impair objective assessment of the standalone LSG operation effects in areas of the study's aim. The study group included 212 patients from our department with complete data of 12 months postoperative follow-up. Demographic and clinical data were gathered prospectively at the follow-up visits, along with repeat measurements of selected laboratory parameters (on the day of the operation, 1 month, 3 months, 6 months, 12 months after LSG). 107 males and 104 females (51\%/49\%) with the average age of 51 (47-57) years were analyzed during the follow-up, with a total of 211 patients subjected to LSG operation technique. Median length of hospital stay was 3 (2-3) days. Postoperative morbidity rate was $6.58 \%$ (16 patients). Bariatric effects were assessed using BMI, total weight loss (\%TWL), percent excess BMI loss (\%EBMIL), and percent excess weight loss (\%EWL) parameters. For calculations of these parameters ideal body weight (IBW) was considered. The criteria for MS diagnosis compliant with AHA-NHLBI guidelines were used in this study. They require the fulfillment of 3 from 5 criteria: abdominal obesity, understood as waist circumference above $80 \mathrm{~cm}$ in women and $>94 \mathrm{~cm}$ in men, dyslipidemia (triglycerides $>150 \mathrm{mg} / \mathrm{dl}$, high-density lipoprotein (HDL) cholesterol fraction $<40 \mathrm{mg} / \mathrm{dl}$ in men and < 50 in women), hypertension (systolic blood pressure $>135$ or diastolic $>85$ ), glucose intolerance (fasting glucose in serum $>100$ ). The first major component of MS is obesity, which, due to the study group intended characteristic, concerned all observed patients. An important point is that we did not take into consideration waist circumference for separate abdominal obesity assessment. However, all our patients had preoperative BMI above $40 \mathrm{~kg} / \mathrm{m}^{2}$, and the absence of abdominal obesity at such BMI values is rarely possible; therefore we assumed that this criterion of MS had been met for all patients involved in this study. Comorbidities were treated before and after the operations by independent specialist doctors and assessed for this study at the follow-up visits, relying on data from interviews with patients and their medical documentation. The most frequent diseases diagnosed among analyzed patients before the follow-up were (listed by frequency of occurrence): arterial hypertension, diagnosed 8-18 years before the study, non-insulin dependent diabetes mellitus, treated pharmacologically from 4 to 7 years long, obstruc- tive sleep apnea, chronic joint disease, depression, varicose veins and coronary artery disease. If we describe all diagnosed comorbidities in numbers, there were 956 comorbidities diagnosed in a total of 211 patients. Note: each single patient may have had suffered from many comorbidities simultaneously. For assessment of the course of comorbidities during the observation period, the patients were divided into two groups: one with observed partial remission of certain comorbidity, understood as relief of some symptoms or their severity reduction, combined with changes in therapy, such as withdrawal of particular medicines or other reduction in treatment intensity, and the second group, in which we observed total disease remission, which means total resolution of symptoms followed by therapy cessation. Biochemical analysis relied on blood samples taken from examined patients and was performed in a hospital laboratory. Parameter norms used in this laboratory were considered for the assessment. Analyzed parameters were as follows: serum levels of bilirubin, creatinine, C-reactive protein (CRP), glucose, insulin, urea, uric acid, alanine aminotransferase (ALT), asparagine aminotransferase (AST), $\gamma$-glutamyltransferase (GGT), total cholesterol (TC), LDL cholesterol, triglycerides (TG), HDL cholesterol, glycated hemoglobin $\left(\mathrm{HbA}_{1 \mathrm{c}}\right)$, selected blood morphology parameters (white blood count (WBCO, red blood count (RBC), hemoglobin level, platelets (PLT)), serum levels of vitamin $B_{12}, D_{3}$, iron, magnesium, lactate dehydrogenase (LDH).

\section{Limitations}

Data assessment for this study was limited to a 12-month patient observation period after undergoing the operation.

\section{Statistical analysis}

Statistical analysis of collected data was performed using Statistica 13.5 software (StatSoft, Tulsa, Oklahoma, United States of America). Continuous values were presented as means with standard deviations, or medians with interquartile ranges as appropriate. Quantitative variables were compared using the repetitive measures ANOVA with posthoc multiple comparison of variations or Friedman's ANOVA with multiple comparison of mean ranges (nonparametric). $P$-values $\leq 0.05$ were considered statistically significant in most calculations. 
Table I. Repeated measures of bariatric effects

\begin{tabular}{|c|c|c|c|c|c|c|}
\hline \multirow[t]{2}{*}{ Parameter } & \multicolumn{5}{|c|}{ Follow-up time } & \multirow[t]{2}{*}{$P$-value } \\
\hline & Day 0 & 1 month & 3 months & 6 months & 12 months & \\
\hline BMI & $\begin{array}{c}45.91 \\
(41.40-50.11) \\
\end{array}$ & $\begin{array}{c}41.56 \\
(37.10-45.48) \\
\end{array}$ & $\begin{array}{c}36.84 \\
(33.65-41.51) \\
\end{array}$ & $\begin{array}{c}33.14 \\
(30.11-38.42) \\
\end{array}$ & $\begin{array}{c}30.37 \\
(26.52-34.76) \\
\end{array}$ & $<0.001$ \\
\hline \%TWL & & $\begin{array}{c}9.77 \% \\
(8.18-11.74 \%) \\
\end{array}$ & $\begin{array}{c}18.07 \% \\
(15.56-20.78 \%) \\
\end{array}$ & $\begin{array}{c}26.04 \% \\
(21.54-29.54 \%)\end{array}$ & $\begin{array}{c}32.23 \% \\
(27.60-37.46 \%)\end{array}$ & $<0.001$ \\
\hline$\% E W L$ & & $\begin{array}{c}22.25 \% \\
(18.02-27.38 \%)\end{array}$ & $\begin{array}{c}40.73 \% \\
(31.87-49.82 \%)\end{array}$ & $\begin{array}{c}59.47 \% \\
(45.25-70.55 \%)\end{array}$ & $\begin{array}{c}73.55 \% \\
(57.69-91.22 \%)\end{array}$ & $<0.001$ \\
\hline \%EBMIL & & $\begin{array}{c}22.25 \% \\
(18.02-27.38 \%) \\
\end{array}$ & $\begin{array}{c}40.73 \% \\
(31.87-49.82 \%)\end{array}$ & $\begin{array}{c}59.47 \% \\
(45.25-70.55 \%)\end{array}$ & $\begin{array}{c}73.55 \% \\
(57.69-91.22 \%)\end{array}$ & $<0.001$ \\
\hline
\end{tabular}

\section{Results}

\section{Bariatric efficiency}

A $p<0.001$ was considered for statistical calculations in this assessment and all results were statistically significant. Median preoperative BMI, calculated on the day of the operation, was $45.91 \mathrm{~kg} / \mathrm{m}^{2}$, ranging from a minimum of $41.40 \mathrm{~kg} / \mathrm{m}^{2}$ to a maximum of $50.11 \mathrm{~kg} / \mathrm{m}^{2}$; therefore all our patients met the criterion of severe obesity $\left(\mathrm{BMI}>40 \mathrm{~kg} / \mathrm{m}^{2}\right)$. After the first month of follow-up, BMI values dropped to a median of 41.56 , with min. and max. values in the range $37-45.48 \mathrm{~kg} / \mathrm{m}^{2}$. At the same time, measurements for \%TWL, \%EWL, \%EBMIL parameter calculations were taken. One month after the performed operations a mean reduction of total body weight of $9.77 \%$ and average loss of excess weight and excess BMI by $22.25 \%$ was observed in all patients. In the following 3, 6 and 12 months after LSG surgery, a positive trend in inducing objective weight loss, therefore also in treating obesity, was sustained. The BMI value was reduced from a medium of 36.84 at 3 months of follow-up to 33.14 in the $6^{\text {th }}$ month and to 30.37 after a year of observation. Total mean BMI reduction after the 12 months of the observation reached a value of $15.54 \mathrm{~kg} / \mathrm{m}^{2}$. Accordingly, total body weight (\%TWL) dropped by a median of $18.07 \% 3$ months after the operation, $26.04 \%$ 6 months and by $32.23 \%$ at the end of our observation. Excess weight loss (\%EWL) and excess BMI loss (\%EBMIL) percentages increased from $40.73 \%$ in the $3^{\text {rd }}$ month of follow-up to $59.47 \%$ in the $6^{\text {th }}$ month and finally to $73.55 \%$ in the $12^{\text {th }}$ month after the surgery. These results are shown in Table I. Figure 1 shows trends in BMI, \%TWL, \%EWL and \%EBMIL changes achieved during the follow-up. In summary, we achieved statistically significant weight loss in all patients of our study group, with preservation of the desired trend in change of these parameters, which allows the prediction of a sustained therapeutic effect in obesity treatment for our patients including after the follow-up.

\section{Assessment of LSG influence on comorbidities}

According to this study subject and the statements featured in the introduction, one of our main tasks was to assess the efficiency of the LSG procedure in treating metabolic syndrome. We aimed not only to assess occurrence of MS components before and after the operation, but also to observe certain biochemical changes, underlying the therapeutic effects. Therefore, our observations in this matter will be described later, along with postoperative glucose

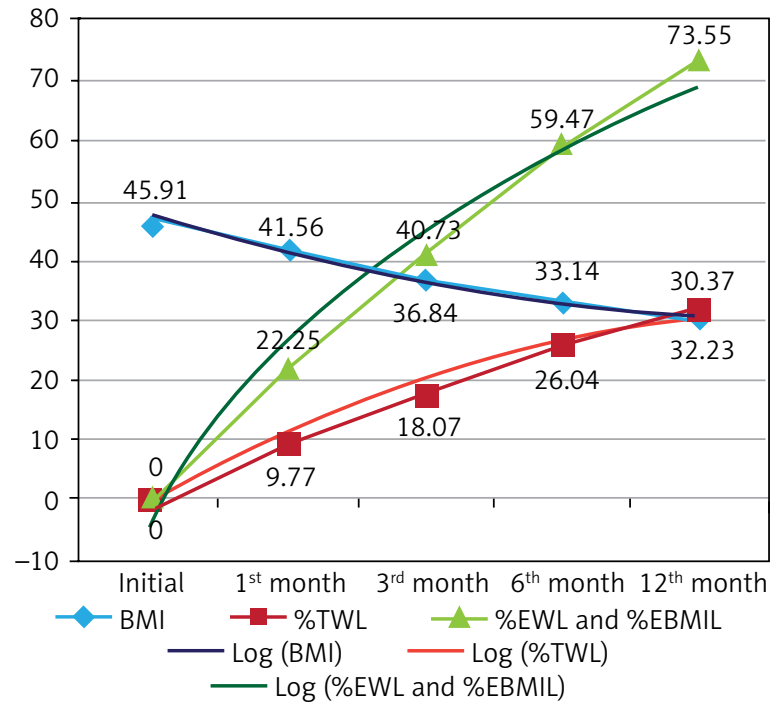

Figure 1. Mean BMI, \%TWL, \%EWL and \%EBMIL changes with logarithmic trends over the time of observation 


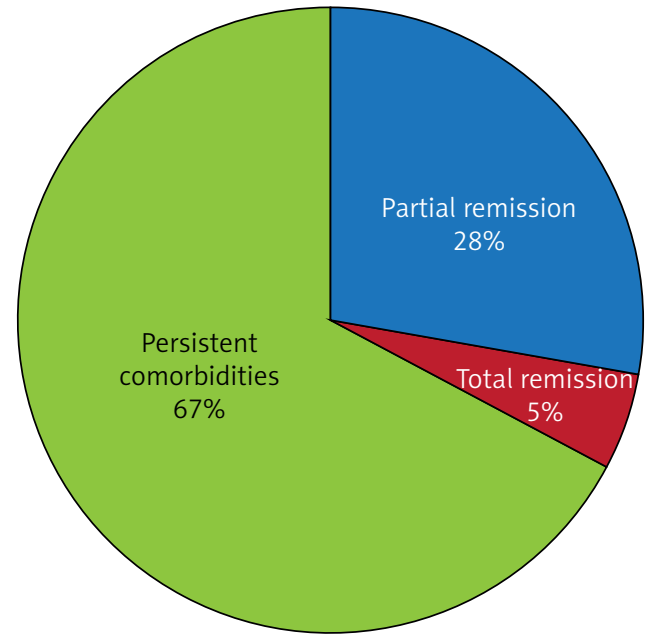

Figure 2. Overall partial and total remission rates observed in study group after 12 months of follow-up

and lipid metabolism profile analysis. Partial remission took place in 273 diseases, giving an overall partial remission rate of $28.56 \%$ after the year of observation. Total remission was observed in 45 diseases, giving an overall total remission rate of $4.71 \%$ at the end of follow-up. These results are shown in Figure 2. The most notable postoperative therapeutic effect, revealed as partial remission rates above approximately $30 \%$ cases and/or total remission rates reaching approximately $10 \%$, was observed in cases of chronic obstructive pulmonary disease (COPD), obstructive sleep apnea, peptic ulcer disease and depression. Substantial recovery rates were likewise observed in patients with coronary artery disease, chronic join disease, deep vein thrombosis, trophic leg ulcerations, gastritis and duodenitis. Partial remission in these diseases occurred in respectively $28.81 \%$ to even $100 \%$ of cases. No total remissions were observed in these illnesses, but the fact that pathogenetic changes caused by them are irreversible and/or their treatment demands performing additional, specialized procedures, should be clearly considered. Lower, but still notable, partial remission percentages were observed in cases of venous diseases, such as hemorrhoids and varicose veins of inferior limbs. Undergoing the LSG procedure had no observed therapeutic influence on gastro-esophageal reflux disease (GERD), esophageal varicose, non-alcoholic fatty liver disease (NAFLD), hiatal hernia, asthma, nephrolithiasis or cholelithiasis in our patients after a year of follow-up. Comorbidities diagnosed among the patients, their frequency and partial or total remission rates observed in our study group are presented in Table II. There were also diseases whose prevalence rose after the procedures in our study group: GERD and esophagitis. Pre- and postoperative occurrence of these comorbidities are shown in Table III.

\section{Efficiency of LSG in treatment of metabolic syndrome components}

Effectiveness of bariatric surgery in the area of obesity treatment is undeniable and was also observed in our follow-up and described in detail above in the "bariatric efficiency" section. From among other diseases forming MS, arterial hypertension $(\mathrm{AH})$ and NIDDM were the two most common comorbidities in our study group and were diagnosed respectively in $85.6 \%$ and $55.92 \%$ of patients before the LSG operation. The impact of undergone surgery on the clinical course of these diseases was observed as achieving better glycemia and blood pressure control in patients, which allowed reduction of previously used pharmacotherapy dosage and/or a change of a few medicines usage into single medicine therapy. Such an effect was notable in $35.59 \%$ cases of NIDDM and in $20.19 \%$ of cases of arterial hypertension after 12 months of the follow-up. Another observed effect in our study was normalization of blood pressure and serum glucose levels without need to sustain previous treatment. Such an impact of the LSG procedure, understood as total remission, was observed in $12.71 \%$ of cases for NIDDM and in $3.85 \%$ cases for $\mathrm{AH}$. Described results are shown in Table II and Figure 3. The influence of this bariatric procedure on NIDDM treatment was analyzed along with certain glucose metabolism parameters. A gradual decrease in mean fasting glucose serum level was observed from 1 to 12 months of observation, reaching a total reduction in medium glucose concentration by $11 \mathrm{mg} / \mathrm{dl}$ at the end of follow-up. Changes in serum glucose levels were followed by significant reduction of mean fasting insulin concentration from 24.2 preoperatively to $8.7 \mu \mathrm{U} / \mathrm{ml}$, which means a total reduction of insulin level by $15.5 \mu \mathrm{U} /$ $\mathrm{ml}$. Raised fasting insulin levels in obese patients are associated with the phenomenon of insulin resistance, underlying development of NIDDM; therefore reduction of this parameter can be identified with 
Table II. Clinical characteristics of study group before undergoing LSG and after 12 months of follow-up

\begin{tabular}{|c|c|c|c|}
\hline Comorbidity type & Before operation, $n(\%)$ & $\begin{array}{l}\text { Partial remission/ } \\
\text { changes in treatment } \\
\text { after } 12 \text { months, } n(\%)\end{array}$ & $\begin{array}{l}\text { Total remission after } \\
12 \text { months, } n(\%)\end{array}$ \\
\hline Hemorrhoids & $40(18.96)$ & $6(15)$ & $n / 0^{*}$ \\
\hline $\begin{array}{l}\text { Gastro-esophageal reflux disease (GERD) } \\
\text { and esophagitis }\end{array}$ & $37(17.53)$ & $n / o^{*}$ & $n / 0^{*}$ \\
\hline $\begin{array}{l}\text { Chronic obstructive pulmonary disease } \\
\text { (COPD) }\end{array}$ & $34(16.11)$ & $15(44.11)$ & $5(14.70)$ \\
\hline Peptic ulcer disease & $31(14.69)$ & $14(45.16)$ & $2(6.45)$ \\
\hline Esophageal varicose & $2(0.95)$ & $n / 0^{*}$ & $n / o^{*}$ \\
\hline Non-alcoholic fatty liver disease (NAFLD) & $27(12.8)$ & $n / o^{*}$ & $n / o^{*}$ \\
\hline Hiatus hernia & $4(1.9)$ & $n / 0^{*}$ & $n / o^{*}$ \\
\hline $\begin{array}{l}\text { Arterial hypertension }(\mathrm{AH}), n(\%) \text {. Du- } \\
\text { ration of arterial hypertension [years], } \\
\text { median }(\mathrm{QQR})=10(8-18)\end{array}$ & $208(85.60)$ & $42(20.19)$ & $8(3.85)$ \\
\hline Coronary artery disease & $59(27.96)$ & $17(28.81)$ & $n / o^{*}$ \\
\hline Obstructive sleep apnea & $91(43.13)$ & $21(23.08)$ & $11(12.09)$ \\
\hline Depression & $68(32.23)$ & $17(25)$ & $4(5.88)$ \\
\hline Asthma & $11(5.21)$ & $n / o^{*}$ & $n / o^{*}$ \\
\hline $\begin{array}{l}\text { Non-insulin dependent diabetes mellitus } \\
(\text { (NIDDM), } n(\%) \text {. Duration of type } 2 \\
\text { diabetes mellitus [years], } \\
\text { median (IQR) }=4(4-7)\end{array}$ & $118(55.92)$ & $42(35.59)$ & $15(12.71)$ \\
\hline Varicose veins & $60(28.44)$ & $7(11.67)$ & $n / 0^{*}$ \\
\hline Chronic joint disease & $73(34.6)$ & $39(53.42)$ & $n / o^{*}$ \\
\hline Nephrolithiasis & $5(2.37)$ & $n / 0^{*}$ & $n / o^{*}$ \\
\hline Cholelithiasis & $11(5.21)$ & $n / o^{*}$ & $n / o^{*}$ \\
\hline Deep vein thrombosis of inferior limbs & $5(2.37)$ & $5(100)$ & $n / 0^{*}$ \\
\hline Trophic leg ulcerations & $14(6.64)$ & $11(78.57)$ & $n / o^{*}$ \\
\hline Gastritis and duodenitis & $58(27.49)$ & $37(63.79)$ & $n / o^{*}$ \\
\hline
\end{tabular}

a reduction in insulin resistance (and may be proven for instance by calculating the HOMA-IR index). Another analyzed laboratory parameter, important in long-term serum glucose levels variability assessment, was glycated hemoglobin $\left(\mathrm{HbA}_{1 \mathrm{c}}\right)$. In the study group we observed reduction of this parameter by $0.6 \%$ over the time of the follow-up, which can be comprehended as better long-term maintenance of reduced serum glucose levels in patients. Described results are presented in Table IV and Figure 4. Another component of MS is dyslipidemia. For the assessment of bariatric procedures' influence on lipid metabolism we analyzed variations in serum levels of the main lipid factions, such as total cholesterol (TC) with HDL and LDL factions and triglycerides. We observed a desired decreasing trend in atherosclerosis-promoting lipid levels, wherein the concentration of the protective HDL fraction rose gradually. TC level was reduced by a medium of $24 \mathrm{mg} / \mathrm{dl}$ over the 12 months after the surgery, the LDL fraction level

Table III. Comorbidities with increased prevalence in study group at the end of the observation

\begin{tabular}{|lcc|}
\hline Comorbidity type & $\begin{array}{c}\text { Before } \\
\text { operation, } n \text { (\%) }\end{array}$ & $\begin{array}{c}\text { After } 12 \\
\text { months of } \\
\text { follow-up, } n \text { (\%) }\end{array}$ \\
\hline $\begin{array}{l}\text { Gastro-oesophageal } \\
\text { reflux disease (GERD) } \\
\text { and esophagitis }\end{array}$ & $44(20.85)$ & $54(25.59)$ \\
\hline
\end{tabular}


dropped by a mean of $24.5 \mathrm{mg} / \mathrm{dl}$, and TG serum concentration decreased by a medium of $51.5 \mathrm{mg} / \mathrm{dl}$. The observed HDL serum level increase reached up to $8 \mathrm{mg} / \mathrm{dl}$ in our study group. These results are shown in Table $V$ and Figure 5. In summary, we observed a significant, positive and multifactorial therapeutic outcome in all aspects of metabolic syndrome after 12 months of follow-up in patients who underwent the LSG procedure.

\section{Analysis of the influence of LSG on biochemical parameters}

Two markers with observed statistically significant increased mean serum concentration after the follow-up were noted - bilirubin and vitamin $D_{3}$. Bilirubin level remained in the normal range during follow-up so fluctuations of its serum concentration had no clinical importance. Whereas medium vita$\min D_{3}$ level was below the norm before the follow-up, a gradual increase of this parameter occurred during the observation period, reaching recommended values from the $1^{\text {st }}$ month after the operation. Laborato-

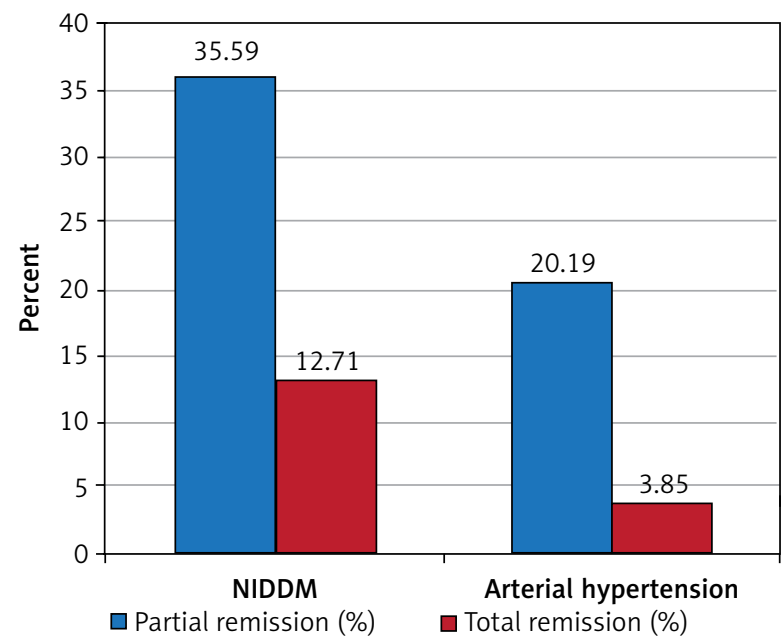

Figure 3. Partial and total remission rates for NIDDM and arterial hypertension cases ry parameters withslightly decreased medium levels after undergoing the LSG operation were as follows: creatinine, CRP, uric acid, ALT, AST, GGT, WBC, RBC, PLT. Their laboratory values also remained within the normal ranges in the whole observation period. In other biochemical markers no statistically or clinically significant influence was observed during the observation period. Described results are presented in Table VI.

\section{Discussion}

Metabolic syndrome is a complex and multifactorial disease, compromising pathological changes, that are burdened with high risk of promoting atherosclerotic diseases, which are the most common death causes among the world's population $[22,23]$. Obesity takes one of the most important places among all MS components, because it is proven to be a standalone factor that induces other components, such as NIDDM, AH and dyslipidemia [24]. Thus, effective therapy demands a multidis-

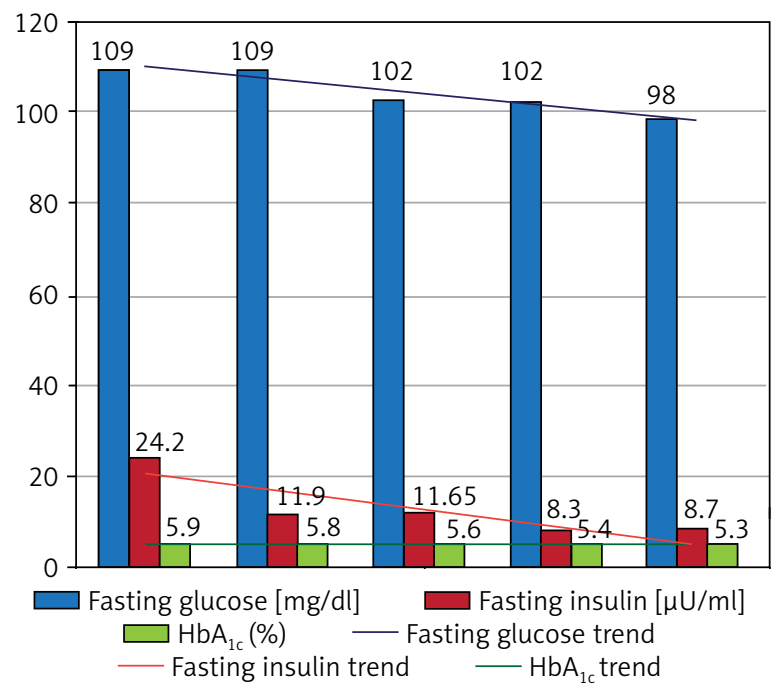

Figure 4. Glucose metabolism parameters' variability with trends over the time of the observation

Table IV. Glucose metabolism parameters' variability over the time of the observation

\begin{tabular}{|lcccccc|}
\hline Laboratory parameter & \multicolumn{5}{c}{ Time of observation } & \multirow{2}{*}{$P$-value } \\
\cline { 2 - 6 } & 0 & 1 month & 3 months & 6 months & 12 months & \\
\hline Fasting glucose $[\mathrm{mg} / \mathrm{dl}]$ & $109(98-133)$ & $109(100-119)$ & $102(95-112)$ & $102(94-110)$ & $98(92-106)$ & $<0.001$ \\
\hline Fasting insulin $[\mathrm{HU} / \mathrm{ml}]$ & $24.2(16.5-34.7)$ & $11.9(8.9-16.1)$ & $11.65(7.9-15.6)$ & $8.3(5.8-15.6)$ & $8.7(6.9-12.8)$ & $<0.001$ \\
\hline $\mathrm{HbA}_{1 \mathrm{c}}(\%)$ & $5.9(5.4-6.6)$ & $5.8(5.4-6.1)$ & $5.6(5.3-5.9)$ & $5.4(5.1-5.7)$ & $5.3(5.1-5.7)$ & $<0.001$ \\
\hline
\end{tabular}


Table V. Lipid factions' serum concentration variability over the time of the observation

\begin{tabular}{|lcccccc|}
\hline Laboratory parameter & \multicolumn{5}{c}{ Time of observation } & \multirow{2}{*}{$P$-value } \\
\cline { 2 - 6 } & 0 & 1 month & 3 months & 6 months & 12 months & \\
\hline TC $[\mathrm{mg} / \mathrm{dl}]$ & $210(178-236.5)$ & $182(154-207)$ & $179(159-200)$ & $189(167-213)$ & $186(163-205)$ & $<0.001$ \\
\hline LDL $[\mathrm{mg} / \mathrm{dl}]$ & $\begin{array}{c}135.5 \\
(101.55-168.5)\end{array}$ & $\begin{array}{c}(93.8-134) \\
\end{array}$ & $122(98-143)$ & $122(98-143)$ & $111(93.5-128)$ & $<0.001$ \\
\hline TG $[\mathrm{mg} / \mathrm{dl}]$ & $164.5(117-202)$ & $148(113-186)$ & $134(102-165)$ & $133(98-176)$ & $113(85-154)$ & $<0.001$ \\
\hline HDL $[\mathrm{mg} / \mathrm{dl}]$ & $47(40.5-60)$ & $37(32-45)$ & $43(36-49)$ & $53(44-65)$ & $55(47-61)$ & $<0.001$ \\
\hline
\end{tabular}

ciplinary approach. Our study revealed that, with the contribution to bariatric surgery development, single therapeutic procedures with notable clinical effectiveness in all aspects of MS were discovered. The LSG is one of the most effective methods for obesity treatment and stands out to fulfill requirements demanded for appropriate therapy in the whole MS area, in cooperation with diet, psychological treatment, lifestyle modifications and all other supportive therapy methods. Such a conclusion is widely confirmed also in current scientific literature [24-26], whereas standalone therapeutic efficiency of mentioned conservative methods usage without bariatric treatment remains unsatisfactory and rarely provides desired positive long-term outcome [27]. When focusing on particular MS components, results achieved in our observation lead to the conclusion that undergoing the LSG operation not only effectively treats existing NIDDM cases, but also enforces normalization of glucose metabolism parameters and prevents development of NIDDM by treating the insulin resistance phenomenon. This conclusion is also confirmed in other publications [28-30]. Observations of a positive clinical impact in treatment were made also in $\mathrm{AH}$ cases during our follow-up and are confirmed in other studies; therefore, bariatric procedures may be considered as a therapeutic solution also in this aspect of MS [31]. Another component of MS, dyslipidemia, is the main factor promoting atherosclerotic changes in blood vessels [32]. The LSG procedure appeared to have a reductive effect in medium serum levels of atherosclerosis-promoting lipid factions (TG, LDL, $\mathrm{TC})$, wherein the observed serum level of the protective HDL fraction rose during the follow-up. Improvements in lipid metabolism caused by bariatric procedures are known in the scientific literature, but each operation technique induce changes with different

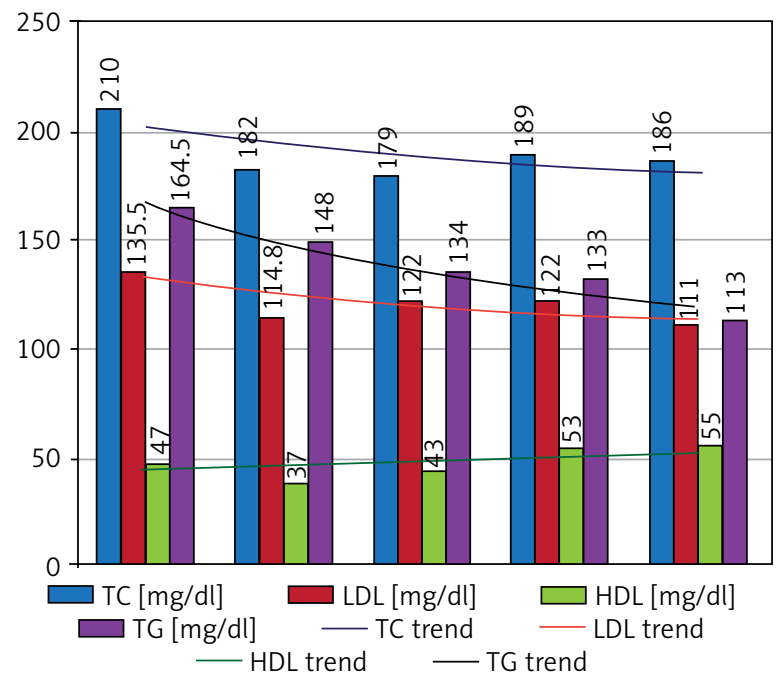

Figure 5. Lipid factions' serum concentration variability over the time of the observation

intensity; thus an appropriate procedure should be selected for dyslipidemia severity in the patient [33, 34]. During the follow-up we also observed pleiotropic improvements in many other obesity-related comorbidities, like other authors assessing patients after bariatric surgery $[35,36]$. Although observed clinical improvements in these diseases are significant and important, complete postoperative resolution in most comorbidities is rather rarely observed [37]. Such a tendency is also notable in our material. Worth emphasizing is the fact that treatment of certain comorbidities, such as coronary artery disease, chronic join disease, trophic leg ulcerations, gastritis, duodenitis, and vein diseases, demand not only eliminating underlying etiological and pathophysiological causes, but also performing specialized therapeutic procedures. Such procedures may be effectively done after bariatric treatment, thanks to the vicious circle-breaking effect achieved along with 
Table VI. Results of repeated measurements of selected laboratory parameters

\begin{tabular}{|c|c|c|c|c|c|c|}
\hline \multirow{2}{*}{$\begin{array}{l}\text { Laboratory parameter, } \\
\text { norms, units }\end{array}$} & \multicolumn{5}{|c|}{ Time of observation } & \multirow[t]{2}{*}{$P$-value } \\
\hline & 0 & 1 month & 3 months & 6 months & 12 months & \\
\hline $\begin{array}{l}\text { Bilirubin } \\
\mathrm{N}: 0.3-1.2 \mathrm{mg} / \mathrm{dl}\end{array}$ & $\begin{array}{c}0.51 \\
(0.39-0.70)\end{array}$ & $\begin{array}{c}0.63 \\
(0.47-0.80)\end{array}$ & $\begin{array}{c}0.65 \\
(0.50-0.87)\end{array}$ & $\begin{array}{c}0.68 \\
(0.50-0.94)\end{array}$ & $\begin{array}{c}0.60 \\
(0.43-0.82)\end{array}$ & $<0.001$ \\
\hline $\begin{array}{l}\text { Creatinine } \\
\mathrm{N}: 0.66-1.43 \mathrm{mg} / \mathrm{dl}\end{array}$ & $\begin{array}{c}0.79 \\
(0.71-0.90)\end{array}$ & $\begin{array}{c}0.86 \\
(0.73-0.96)\end{array}$ & $\begin{array}{c}0.85 \\
(0.73-1.01)\end{array}$ & $\begin{array}{c}0.82 \\
(0.68-1.01)\end{array}$ & $\begin{array}{c}0.77 \\
(0.69-0.89)\end{array}$ & $<0.001$ \\
\hline $\begin{array}{l}\text { CRP } \\
\mathrm{N}:<10 \mathrm{mg} / \mathrm{dl}\end{array}$ & $\begin{array}{c}7.3 \\
(4-10.5)\end{array}$ & $\begin{array}{c}5.89 \\
(2.80-10.73)\end{array}$ & $\begin{array}{c}5.56 \\
(2.81-8.3)\end{array}$ & $\begin{array}{c}5.83 \\
(2.4-10.02)\end{array}$ & $\begin{array}{c}2.44 \\
(0.9-6.8)\end{array}$ & $<0.001$ \\
\hline $\begin{array}{l}\text { Urea } \\
\mathrm{N}: 15-40 \mathrm{mg} / \mathrm{dl}\end{array}$ & $\begin{array}{c}34 \\
(29-43)\end{array}$ & $\begin{array}{c}31 \\
(25-37)\end{array}$ & $\begin{array}{c}31.5 \\
(24-37)\end{array}$ & $\begin{array}{c}32 \\
(26-41.5)\end{array}$ & $\begin{array}{c}34 \\
(25-43)\end{array}$ & $<0.001$ \\
\hline $\begin{array}{l}\text { Uric acid } \\
\mathrm{N}: 2-7 \mathrm{mg} / \mathrm{dl}\end{array}$ & $\begin{array}{c}6.41 \\
(5.3-7.7)\end{array}$ & $\begin{array}{c}6.66 \\
(5.36-7.89)\end{array}$ & $\begin{array}{c}5.69 \\
(4.65-6.80)\end{array}$ & $\begin{array}{c}5.44 \\
(4.61-6.36)\end{array}$ & $\begin{array}{c}6.08 \\
(5.20-6.99)\end{array}$ & $<0.001$ \\
\hline $\begin{array}{l}\text { ALT } \\
\mathrm{N}: 5-50 \mathrm{IU} / \mathrm{l}\end{array}$ & $\begin{array}{c}34.1 \\
(23.3-46.5)\end{array}$ & $\begin{array}{c}35.6 \\
(26-46)\end{array}$ & $\begin{array}{c}25 \\
(18.5-34)\end{array}$ & $\begin{array}{c}22 \\
(16-32)\end{array}$ & $\begin{array}{c}22 \\
(16-28.7)\end{array}$ & $<0.001$ \\
\hline $\begin{array}{l}\text { AST } \\
\mathrm{N}: 5-50 \mathrm{IU} / \mathrm{l}\end{array}$ & $\begin{array}{c}28 \\
(20-45)\end{array}$ & $\begin{array}{c}27.4 \\
(22-35.5)\end{array}$ & $\begin{array}{c}23 \\
(18.1-29)\end{array}$ & $\begin{array}{c}21.65 \\
(16-28.55)\end{array}$ & $\begin{array}{l}21.05 \\
(17-26)\end{array}$ & $<0.001$ \\
\hline $\begin{array}{l}\text { GGT } \\
\text { N: } 10-100 \mathrm{U} / \mathrm{l}\end{array}$ & $\begin{array}{c}34 \\
(24.9-55)\end{array}$ & $\begin{array}{c}22.5 \\
(16.85-32.9)\end{array}$ & $\begin{array}{c}19.8 \\
(14-27.1)\end{array}$ & $\begin{array}{c}16.3 \\
(11.7-26.2)\end{array}$ & $\begin{array}{c}17.2 \\
(12.5-30.7)\end{array}$ & $<0.001$ \\
\hline $\begin{array}{l}\text { WBC } \\
\text { N: } 4.8-10.8 \times 10^{3} / \mu \mathrm{l}\end{array}$ & $\begin{array}{c}7.67 \\
(6.36-8.8)\end{array}$ & $\begin{array}{c}6.4 \\
(5.2-7.89)\end{array}$ & $\begin{array}{c}6.47 \\
(5.67-8.12)\end{array}$ & $\begin{array}{c}7.45 \\
(6-9.06)\end{array}$ & $\begin{array}{c}6.84 \\
(5.5-7.93) \\
\end{array}$ & $<0.001$ \\
\hline $\begin{array}{l}\text { RBC } \\
\text { N: } 4.2-6.1 \times 10^{6} / \mu \mathrm{l}\end{array}$ & $\begin{array}{c}4.92 \\
(4.59-5.29)\end{array}$ & $\begin{array}{c}4.99 \\
(4.65-5.26)\end{array}$ & $\begin{array}{c}4.68 \\
(4.34-5.07)\end{array}$ & $\begin{array}{c}4.84 \\
(4.5-5.25)\end{array}$ & $\begin{array}{c}4.78 \\
(4.43-5.09)\end{array}$ & $<0.001$ \\
\hline $\begin{array}{l}\text { Hemoglobin } \\
\mathrm{N}: 12-18 \mathrm{~g} / \mathrm{dl}\end{array}$ & $\begin{array}{c}13.8 \\
(12.5-14.7)\end{array}$ & $\begin{array}{c}13.8 \\
(12.8-14.8)\end{array}$ & $\begin{array}{c}13.7 \\
(12.8-14.9)\end{array}$ & $\begin{array}{c}13.7 \\
(12.5-14.5)\end{array}$ & $\begin{array}{c}13.8 \\
(12.8-14.7)\end{array}$ & 0.298 \\
\hline $\begin{array}{l}\text { PLT } \\
\text { N: } 150-400 \times 10^{3} / \mu \mathrm{l}\end{array}$ & $\begin{array}{c}256.5 \\
(210-324)\end{array}$ & $\begin{array}{c}237 \\
(200-283)\end{array}$ & $\begin{array}{c}227 \\
(198-265)\end{array}$ & $\begin{array}{c}250 \\
(209-305)\end{array}$ & $\begin{array}{c}235 \\
(194-280)\end{array}$ & $<0.001$ \\
\hline $\begin{array}{l}\text { Vit. } B_{12} \\
\mathrm{~N}: 118-664 \mathrm{pmol} / \mathrm{l}\end{array}$ & $\begin{array}{c}86.8 \\
(62.4-117.2)\end{array}$ & $\begin{array}{c}86.23 \\
(65.8-115.3)\end{array}$ & $\begin{array}{c}78.9 \\
(59.9-114.5)\end{array}$ & $\begin{array}{c}91.8 \\
(58.6-132.5)\end{array}$ & $\begin{array}{c}78.6 \\
(51.35-107.55)\end{array}$ & 0.051 \\
\hline $\begin{array}{l}\text { Iron } \\
\mathrm{N}: 37-158 \mathrm{mg} / \mathrm{dl}\end{array}$ & $\begin{array}{c}95 \\
(77-124)\end{array}$ & $\begin{array}{c}71.5 \\
(59-89)\end{array}$ & $\begin{array}{c}77 \\
(65-90)\end{array}$ & $\begin{array}{c}86 \\
(61-115)\end{array}$ & $\begin{array}{c}92 \\
(67-112)\end{array}$ & 0.050 \\
\hline $\begin{array}{l}\text { Magnesium } \\
\mathrm{N}: 1.6-2.3 \mathrm{mg} / \mathrm{dl}\end{array}$ & $\begin{array}{c}0.78 \\
(0.72-0.85)\end{array}$ & $\begin{array}{c}0.83 \\
(0.78-0.89)\end{array}$ & $\begin{array}{c}0.86 \\
(0.8-0.91)\end{array}$ & $\begin{array}{c}0.84 \\
(0.77-0.91)\end{array}$ & $\begin{array}{c}0.87 \\
(0.8-0.93)\end{array}$ & 0.528 \\
\hline $\begin{array}{l}\text { LDH } \\
\mathrm{N}: 120-230 \mathrm{U} / \mathrm{l}\end{array}$ & $\begin{array}{c}214 \\
(193-238)\end{array}$ & $\begin{array}{c}168.5 \\
(97.5-207)\end{array}$ & $\begin{array}{c}153 \\
(89.4-202)\end{array}$ & $\begin{array}{c}175 \\
(125.3-216)\end{array}$ & $\begin{array}{c}156.5 \\
(78.9-205)\end{array}$ & 0.068 \\
\hline $\begin{array}{l}\text { Vit. } D_{3} \\
\mathrm{~N}: \geq 20 \mathrm{ng} / \mathrm{ml}\end{array}$ & $\begin{array}{c}17.45 \\
(11-22.7)\end{array}$ & $\begin{array}{c}22.2 \\
(15.8-29.3)\end{array}$ & $\begin{array}{c}27.35 \\
(21.6-34.3)\end{array}$ & $\begin{array}{c}26.45 \\
(18.95-33.05)\end{array}$ & $\begin{array}{c}24.45 \\
(19.7-32.5)\end{array}$ & $<0.001$ \\
\hline
\end{tabular}

weight loss, which also leads to elimination of the cause of the disease. Therefore bariatric procedures should be considered as a first step and necessary treatment in these diseases, despite the fact that their standalone therapeutic effect may not seem to be sufficient [38]. Clinically desirable reduction of certain biochemical markers, such as creatinine, CRP, uric acid, ALT, AST, GGT, connected with renal and hepato-biliary function or inflammatory activity, was also observed in our study group, but values of these parameters remained in the normal ranges in the whole observation period. Other authors provide information that the overall long-term (above > 12 months) influence of bariatric treatment on kidney, liver and inflammatory function is positive, so these results could be considered as a good prognostic factor also in our assessment [39-42]. C-reactive protein and other inflammatory marker levels' postoperative increase is also proven to be diagnostic in operation technique related complications, such as 
bleeding or anastomosis leak [43], but the patients who developed such complications were excluded from the follow-up, and therefore mentioned conclusions on the postoperative inflammatory function could be stated. Worth emphasizing is that there are many other factors influencing overall postoperative outcome, that are not connected with operative technique. Patient compliance, preoperative clinical status, perioperative care standards and clinical bariatric experience are proven to be significant factors not only in procedure-related complication risk, but also in postoperative therapeutic efficacy and should also be considered in assessment of a specific bariatric procedure's influence on certain comorbidities [44-46]. Our follow-up period was limited to 1 year after the performed LSG operation, but the data collection from many patients who participated in this study and newly acquired patients is still in progress to be assessed in further studies. The contemporary medical knowledge base already provides viable information on bariatric treatment long-term efficiency in aspects of obesity, metabolic syndrome and comorbidities treatment, but many authors claim that the data in this issue are still insufficient. Analysis of 3- and 5-year long follow-ups confirms efficient weight loss and a major improvement in obesity-related comorbidities, but some also report significant weight regain followed by an NIDDM remission rate decrease [47-49]. Positive changes in lipid profile after undergoing the LSG operation appear to be statistically significant only in short-term observations, but seem to remain at desirable levels over time [50].

\section{Conclusions}

Laparoscopic sleeve gastrectomy is an effective method of treatment for morbid obesity, especially in cases meeting criteria for metabolic syndrome, provides a significant positive clinical outcome in obesity-related comorbidities and induces positive changes in biochemical markers, such as creatinine, CRP, uric acid, ALT, AST, GGT, that might be considered as a good prognostic factor in assessment of kidney, liver and inflammatory function. According to the aim of this study and observation results we consider that the follow-up was successful for all 211 subjected patients. Although postoperative complications occurred in our study group and were not evaluated in this particular follow-up, expected positive effects in areas included in this study's subject were achieved. The general conclusion is that LSG is one of the bariatric procedures that should be recommended as a main and first step complex therapeutic solution for metabolic syndrome and other morbid obesity cases in compliance with good clinical practice and evidence-based medicine rules.

\section{Conflict of interest}

The authors declare no conflict of interest.

\section{References}

1. Meldrum DR, Morris MA, Gambone JC. Obesity pandemic: causes, consequences, and solutions - but do we have the will? Fertil Steril 2017; 107: 833-9.

2. Hady HR, Zbucki RL, Łuba ME, et al. Obesity as a social disease and the influence of environmental factors on BMI in own material. Adv Clin Exp Med 2010; 19: 369-78.

3. Hruby A, Hu FB. The epidemiology of obesity: a big picture. Pharmacoeconomics 2015; 33: 673-89.

4. Alberti KG, Eckel RH, Grundy SM, et al. Harmonizing the metabolic syndrome. A joint interim statement of the International Diabetes Federation Task Force on Epidemiology and Prevention; National Heart, Lung, and Blood Institute, American Heart Association, World Heart Federation, International Atherosclerosis Society and International Association for the Study of Obesity. Circulation 2009; 120: 1640-5.

5. Hu G, Qiao Q, Tuomilehto J, et al. Prevalence of the metabolic syndrome and its relation to all-cause and cardiovascular mortality in non-diabetic European men and women. Arch Intern Med 2004; 164: 1066-76.

6. Isoma B, Almgren P, Tuomi T, et al. Cardiovascular morbidity and mortality associated with the metabolic syndrome. Diabetes Care 2001; 24: 683-9.

7. Lakka HM, Laaksonen DE, Lakka TA, et al. The metabolic syndrome and total and cardiovascular disease mortality in middle-aged men. JAMA 2002; 288: 2709-16.

8. Jastrzębska-Mierzyńska M, Ostrowska L, Hady HR, et al. The impact of bariatric surgery on nutritional status of patients. Videosurgery Miniinv 2015; 10: 115-24.

9. Vidal J, Ibarzabal A, Romero F, et al. Type 2 diabetes mellitus and the metabolic syndrome following sleeve gastrectomy in severely obese subjects. Obes Surg 2008; 18: 1077-82.

10. Clinical Issues committee of the American Society for Metabolic and Bariatric Surgery: Sleeve gastrectomy as a bariatric procedure. Surg Obes Rel Dis 2007; 3: 573-6.

11. Kral JG, Naslund E. Surgical treatment of obesity. Nat Clin Pract Endocrinol Metab 2007; 3: 574-83.

12. El Chaar ML, Hammoud N, Ezeji G, et al. Laparoscopic sleeve gastrectomy versus laparoscopic Roux-en-Y gastric bypass: a single center experience with 2 years follow-up. Obes Surg 2015; 25: 254-62.

13. Xinze S, Shahzeer K. A review of laparoscopic sleeve gastrectomy formorbid obesity. Obes Surg 2010; 20: 1171-7. 
14. Buchwald $\mathrm{H}$, Avidor $\mathrm{Y}$, Brawnwald $\mathrm{E}$, et al. A systematic review and meta-analysis. JAMA 2004; 292: 1724-37.

15. Harshit G, Pratyusha P, Sandeep A, et al. Comparative study of outcomes following laparoscopic Roux-en-Y gastric bypass and sleeve gastrectomy in morbidly obese patients: a case control study. World J Gastrointest Endosc 2017; 9: 162-70.

16. Dardzińska JA, Kaska Ł, Proczko-Stepaniak M, et al. Fasting and postprandial acyl and desacyl ghrelin and the acyl/desacyl ratio in obese patients before and after different types of bariatric surgery. Videosurgery Miniinv 2018, 13: 366-75.

17. Wróblewski E, Świdnicka-Siergiejko A, Hady HR, et al. Variation in blood levels of hormones in obese patients following weight reduction induced by endoscopic and surgical bariatric therapies. Cytokine 2016; 77: 56-62.

18. Hady HR, Dadan J, Gołaszewski P. 100 obese patients after laparoscopic adjustable gastric banding - the influence on BMI, gherlin and insulin concentration, parameters of lipid balance and co-morbidities. Adv Med Sci 2012; 57: 58-64.

19. Budzyński A, Major P, Głuszek S, et al. Polskie rekomendacje w zakresie chirurgii bariatrycznej i metabolicznej. Med Prakt Chir 2016; 6: 13-25.

20. von Elm E, Altman DG, Egger M, et al. The Strengthening the Reporting of Observational Studies in Epidemiology (STROBE) statement: duidelines for reporting observational studies. Int J Surg 2014; 12: 1495-9.

21. Motheral B, Brooks J, Clark MA, et al. A checklist for retrospective database studies - report of the ISPOR task force on retrospective databases. Value Heal 2003; 6: 90-7.

22. Mathieu P, Philippe LP, Després JP: Metabolic syndrome: the danger signal in atherosclerosis. Vasc Health Risk Manag 2006; 2: 285-302

23. WHO Fact Sheets: The top 10 causes of death. https://www who.int/news-room/fact-sheets/detail/the-top-10-causes-ofdeath. 24.05.2018

24. Thang S, Mike EJ. A clinical perspective of obesity, metabolic syndrome and cardiovascular disease. JRSM Cardiovasc Dis 2016; 5: 2048004016633371.

25. Cordero P, Li J, Oben JA. Bariatric surgery as a treatment for metabolic syndrome. J R Coll Physicians Edinb 2017; 47: 364-8.

26. Boniecka I, Wileńska H, Jeznach-Steinhagen A, et al. Stress as a factor contributing to obesity in patients qualified for bariatric surgery - studies in a selected group of patients (a pilot study). Videosurgery Miniinv 2017; 12: 60-7.

27. Kostecka M, Bojanowska M. Problems in bariatric patient care - challenges for dieticians. Videosurgery Miniinv 2017; 12: 207-15.

28. Batterham RL, Cummings DE. Mechanisms of diabetes im provement following bariatric/metabolic surgery. Diabetes Care 2016; 39: 893-901.

29. Zalewska A, Knaś M, Niczyporuk M, et al. Salivary lysosomal exoglycosidases profiles in patients with insulin-dependent and noninsulin-dependent diabetes mellitus. Adv Clin Exp Med 2013; 22: 659-66.

30. Bužga M, Holéczy P, Švagera Z, et al. Effects of sleeve gastrectomy on parameters of lipid and glucose metabolism in obese women -6 months after operation. Videosurgery Miniinv 2013; 8: $22-8$.
31. Schiavon CA, Bersch-Ferreira AC, Santucci EV, et al. Effects of bariatric surgery in obese patients with hypertension. The GATEWAY Randomized Trial (Gastric Bypass to Treat Obese Patients With Steady Hypertension). Circulation 2018; 137: 1132-42.

32. Linton MF, Yancey PG, Davies SS, et al. The role of lipids and lipoproteins in atherosclerosis. Endotext Jan 3, 2019. Available at: https://www.ncbi.nlm.nih.gov/books/NBK343489/

33. Heffron SP, Parikh A, Volodarskiy A, et al. Changes in lipid profile of obese patients following contemporary bariatric surgery: a meta-analysis. Am J Med 2016; 129: 952-9.

34. Milonea M, Lupo R, Maietta P, et al. Lipid profile changes in patients undergoing bariatric surgery: a comparative study between sleeve gastrectomy and mini-gastric bypass. Int J Surg 2015; 14: 28-32.

35. Zhang N, Maffei A, Cerabona T, et al. Reduction in obesity-related comorbidities: is gastric bypass better than sleeve gastrectomy? Surg Endosc 2013; 27: 1273-80.

36. Major P, Stefura T, Małczak P, et al. Postoperative care and functional recovery after laparoscopic sleeve gastrectomy vs. laparoscopic Roux-en-Y gastric bypass among patients under ERAS protocol. Obes Surg 2018; 28: 1031-9.

37. Noria SF, Grantcharov T. Biological effects of bariatric surgery on obesity-related comorbidities. Can J Surg 2013; 56: 47-57.

38. Chan WH, Bin Chet TT, Eng A. 5-years long-term clinical outcome after bariatric surgery - a multi-ethnic Asian population in Singapore. Diabetes Obes Metab 2018; 20: 1762-5.

39. Chang AR, Morgan E, Sankar D, et al. Bariatric surgery and kidney-related outcomes. Kidney Int Rep 2017; 2: 261-70.

40. Major P, Pędziwiatr M, Rubinkiewicz M, et al. Impact of bariatric surgery on non-alcoholic fatty liver disease. Pol Przegl Chir 2017; 89: 1-4.

41. Hafida S, Mirshahi T, Nikolajczyk BS. The impact of bariatric surgery on inflammation: quenching the fire of obesity? Curr Opin Endocrinol Diabetes Obes 2016; 23: 373-8.

42. Morshed G, Samah M. Impact of post-laparoscopic sleeve gastrectomy weight loss on C-reactive protein, lipid profile and CA-125 in morbidly obese women. Videosurgery Miniinv 2015; 10: $521-6$.

43. Frask A, Orłowski M, Dowgiałło-Wnukiewicz N, et al. Clinical evaluation of C-reactive protein and procalcitonin for the early detection of postoperative complications after laparoscopic sleeve gastrectomy. Videosurgery Miniinv 2017; 12: 160-5.

44. Stefura T, Skomarovska O, Wysocki M, et al. Challenges associated with bariatric surgery - a multi-center report. Videosurgery Miniinv 2019 In press DOI: https://doi.org/10.5114/ wiitm.2019.81370.

45. Major P, Wysocki M, Janik M, et al. Impact of age on postoperative outcomes in bariatric surgery. Acta Chir Belg 2018; 118: 307-14.

46. Major P, Małczak P, Wysocki M, et al. Bariatric patients' nutritional status as a risk factor for postoperative complications, prolonged length of hospital stay and hospital readmission: aretrospective cohort study. Int J Surg 2018; 56: 210-4.

47. Aminian A, Brethauer S, Andalib A, et al. Can sleeve gastrectomy "cure" diabetes? Long-term metabolic effects of sleeve gastrectomy in patients with type 2 diabetes. Ann Surg 2016; 264: 674-81. 
48. Carlos H. Five-year outcomes of laparoscopic sleeve gastrectomy as a primary procedure for morbid obesity: a prospective study. World J Gastrointest Surg 2017; 9: 109-17.

49. Kowalewski P, Olszewski R, Walędziak M, et al. Long-term outcomes of laparoscopic sleeve gastrectomy - a single-center, retrospective study. Obes Surg 2018; 28: 130-4.

50. Golomb I, Ben David M, Glass A, et al. Long-term metabolic effects of laparoscopic sleeve gastrectomy. JAMA Surg 2015; 150: 1051-7.

Received: 6.02.2019, accepted: 16.03.2019. 